\title{
Performance indices of project companies virtual divisions in the construction in CAD conditions
}

\author{
Sergey Sinenko ${ }^{1}$, Anastasiia Slavina ${ }^{1, *}$ \\ ${ }^{1}$ Moscow State University of Civil Engineering, Yaroslavskoe shosse, 26, Moscow, 129337, Russia
}

\begin{abstract}
At the present time we consider the construction operations development triggered by the modern technologies development. The electronics, robotics, artificial intelligence, wireless technologies and more became the present-day production attribute. The creation of virtual organizations has become the expected solution of business communities. Following in the footsteps of information boom, in this article we consider the problem of construction field virtualisation, in particular: characteristics of virtuality and virtual structures operation, in-virtual organization work peculiarities, difficulties faced by the company manager with such form of work and criteria for the assessment of organization efficiency. The virtual organization is deemed to be the voluntary cooperation form of partners, aimed at project work type. This is the unique team, the basic resources of which are time and technologies. In general such organization does not have any geographical origin and it works using the Internet. In the context given herein, the virtual structure is considered in CAD conditions that is based on the high degree of construction field IT. Specific relations between the employees make the impact on the work process, therefore a number of both subjective (social, individual, etc.) and objective (financial) indices are given.
\end{abstract}

\section{Introduction}

The goal of the work to find the basic characteristics of construction used in the design and work with the staff. Based on the writings of the founders of the theories of management (Frederick Taylor, Henri Fayol, Max Weber and others) we are aware of how important the build system organization and context between its elements. More modern literature gives an opportunity to assess the similarity of the phenomena occurring in the construction industry, and address to the patron of foreign colleagues extends understanding of the processes.

Construction activities have always been considered as a hard and responsible affair, requiring for work in earnest. The organization of construction operations is the interrelated training system for execution of individual work types, determination and provision of a

${ }^{*}$ Corresponding author: slavinaay@mgsu.ru 
general order, priority and time period of execution, supply of all types of resources to ensure the efficiency and workmanship of facilities construction.

What does the construction company need for the success? According to researches, the personnel plays a valuable role in the company because the basic resource in construction activities is a competent team, the indices of their performance assessment hinge on it.

Maintenance of the company liability for its activities implementation, including the expenditure of financial resources and the results achievement, is given in Figure 1.

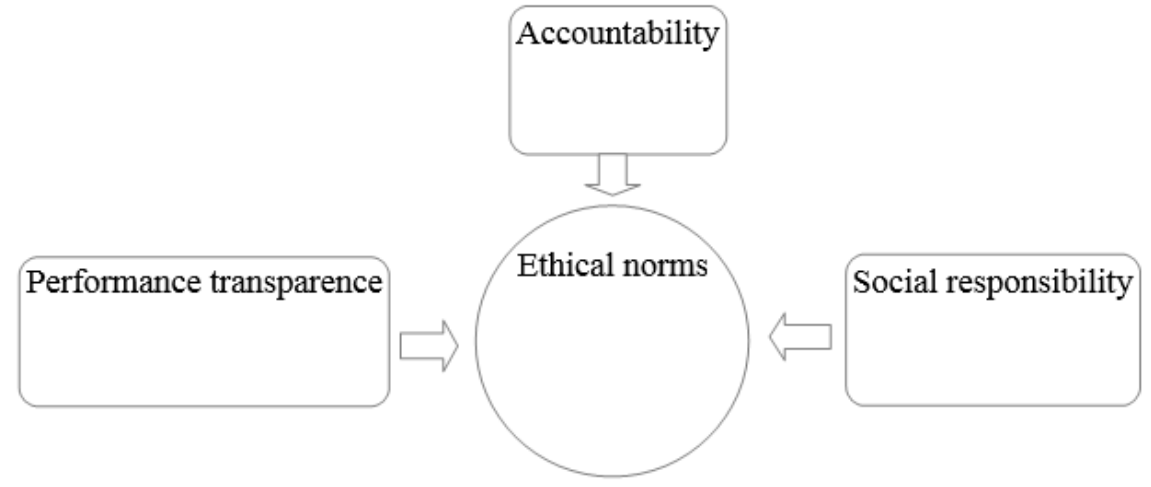

Fig. 1. Maintenance of the company liability.

A problem of accountability results from the difficult of people remote management, first of all, at creation and functioning of virtual divisions [1,2,3]. We may state that the most quantity of virtual divisions has been created at the project companies, working in CAD conditions.

\section{The experimental section}

It is necessary to define what is called a virtual organization, what features distinguish and the difficulties faced by the Organization of its kind. Relying on the development of Kataev V.A., Serdyuk O.V., E.N. and S.N. Bolshakova Course we describe modern concepts that formed during the last 10-15 years. Virtual organization means the independent network of members (individual person, company, trust etc.), the task of which is the creation and implementation of goods or service using state-of-the-art IT solutions [4]. On this basis we can give it the following characteristics:

- voluntary association of the organizations ore their members;

- allocation of the organization total resources;

- absence of the exact geographical center;

- availability of multiple horizontal links;

- principles of virtual organization management comply with modern trends of management;

- use of computer communication by means of computer networks, etc.

The most important characteristic of virtual organization is the open dynamic network structure. The key advantage of virtual organizations is the possibility to choose and use the best resources, knowledges and capabilities at lower time expenditures. This advantage and the network organization provide with such basic specific advantages of virtual companies as follows:

1. speed of market order execution;

2. aggregate costs decrease;

3. more complete satisfaction of customer requirements; 
4. flexible adaptation towards environmental changes;

5. lowering of barriers for entry into new markets $[5,6]$.

Functionality of virtual organization structure, in particular - the single information center, which is meant for gathering of information on deviations, their recording, fast generation of control actions with account of failures type checking, provision of such information to the management, and in case of non-typical failure (no information available in the system relating to such failure) - provision for communications through the link "management —implementation link" as soon as possible.

Operation of virtual organization directly depends on the manager skills and abilities, i.e. on the cooperation level between "flexible technologies"- people and physical systems. The difficulty of cooperation is provided by the uniqueness of human consciousness in contrast with standard computer programs and systems. The creation of adapted components allows providing reliability of operation with electronic mechanical systems [7].

Furthermore, the specific feature of virtual organization is its employees, having quite specific relations among themselves. The work in such organization requires for high intellectual abilities both from the manager and from the members. With account of project nature of work, wide geographical sector, involvement of a great number of experts and lack of activity timetable in itself, the employee of virtual organization shall have the following competences:

- shall plan properly the working hours, set targets and choose the ways of targets achievement;

- shall have spacious mind, get into work on project quickly, and switch quickly, if there are several projects;

- shall know one or several foreign languages (especially in international company);

- shall have fresh thinking, have a skill to find creative solutions, take a creative approach to the purpose [8].

These are the innovative teams, the result of which depends on a potential of each member and its involvement into work process. Under specific rules within organization, in particular - under transparent control system for ownership of ideas, for working hours and its payments, we may state that the system is more than viable, but it needs for specified actions of HR manager.

The most serious problem for the managers of virtual organizations is the cooperation management between "flexible technologies". A human is unique, and technologies (computers) work in the same manner. The main requirement is the following: the technologies shall provide people the opportunity to carry out work. There are a lot of conditions, approaches to the experts use within one or another technology: creative (Creatively - C); easy (Easily - E); in compliance with high standards (Standard- S); in time (Timely - T); accountable (Accountably - A) [9,10].

Directly in the construction operations, the virtual division means the employees team, in general, created on a temporary basis for the local problems solution (creative teams, research teams for performance of $R \& D$ topics, projects, etc.) associated with the participation of experts on a multi-disciplinary basis.

In the area of construction activities and construction design it has been said that it is necessary to create the groups of multidiscipline experts with the equal rights, who bear a common responsibility for their performance results and who carry out a division of labour in equal measure. At the present time the experts work is evaluated with a number of indices. It is important to understand that the indices shall be measurable - it is only a number that could be trusted, as the other evaluation methods have the significant subjective nature. 
To perform the assessment of project works efficiency it is necessary to specify the following characteristics:

- existing and forthcoming contacts;

- time factor (compliance with work schedule);

- goods or services quality (deviance from a norm);

- communication level (work with clients);

- HR management (engagement, personnel movement depending on high-priority tasks).

The most important type of analysis from ones above listed is the analysis of the company activities financial results. The purpose of such analysis is the efficiency improvement of the construction company activities following the maximum use of all resources. The analysis includes the researches of the whole social and economic, technological, legal processes, the principle of the control systems formation and functioning [11].

The project group has three "basic" management tools — project time, budget and quality. The projects efficiency depends largely on the management by these three tools. Thus, one of the methods for project efficiency increase is the experts team orientation to achievement of the project three main purposes:

- lowering of costs for project performance;

- decrease of time expenditures;

- achievement (increase) of the project quality criteria.

\section{The results section}

The results of the practical part of the performance indicators will be a virtual organization. An index is a relative or absolute value for evaluation of tasks and purposes specified. Evaluation is based on the data analysis, on the qualitative and quantitative characteristics.

The basic results of the project team activities are:

- achievement of project purposes or the purposes of its life cycle stage;

- solving of tasks in hand and achievement of project results on time and at given resource constraints.

There are 2 groups of assessment indices of the project division performance in the construction: objective (financial) and subjective (social, personal, sensuous) indices.

The objective indices are:

1. Fruitfulness of activity. Using this index, it is possible to understand, whether the final result of stated purposes was obtained;

2. Returns. It allows specifying the minimum labour efforts at obtaining the final result; efficiency - the measurement of quantity and quality of output products for certain period;

3. Earning power - the index of efficient resource utilization, specifying the company economic efficiency and its profitability;

4. Waste-free. The less waste is left in production so much the less the company pollutes environment. The waste-free index takes into account all environmental requirements applicable to process technologies;

5. Energy consumption. The main rule while the assessment of this index is a low energy consumption on the production processes consequently having an impact on the company efficiency in general. The lower power, the higher efficiency of the company.

The subjective assessment indices of the project team performance in the construction are:

1. Personnel engagement and view of life. This index of performance efficiency is the evidence of the human internal resources strength, of his psychologic role in the society, of his physical and mental training extent. The extent of engagement is estimated by the 
employee involvement to production process, by the extent of his energy expenditure during the work on project. The employee engagement into social life of the company is also taken into account;

2. Extent of employee satisfaction. This index describes the employee attitude to his work and his satisfaction by his labour indices and by his cooperation in the team;

3. Personnel stability. This is very important index of performance efficiency, its analysis requires for proportions to be considered. In general this index describes the personnel turnover. In the turnover is high, it indicates the organization instability and the decrease of its efficient labour. If there is no new personnel for a long time, it is also deemed to be bad for the company successful work.

4. Company spirit. The index describes the team cohesion, its performance to the company common concept and the tendency to achievement of high team indices. Teamwork skills of the employee is the important component for avoidance of conflicts and disputes, for achievement of the significant indices in work on the specified project and for successful company work in all areas. This index of performance efficiency points at the right-organized structure of the team members cooperation, at the effectiveness of the management personnel and implemented managing approaches [12].

The system of assessment indices of the division performance allows evaluating all functions and resources of the production stages and their financial component. It includes both the economic and social indices requiring for the constant control:

- at all production process stages;

- at all stages of the tasks planning and statement;

- at every step of these tasks achievement.

Not all the performance efficiency indices in the system have the same value. There are the main (general) indices, and secondary ones responsible for the specialized functional area. The general indices value is meant for final purpose results determination and for developed strategy performance. The value of the performance efficiency functional indices shows the company growth rate at the production process specific area, and helps to eliminate the deterrents for high indices achievement.

The main performance indices of project companies divisions in the construction are given in the following table.

Table 1. Performance indices of company divisions (groups).

\begin{tabular}{|l|c|}
\hline \multicolumn{1}{|c|}{ Indices } & $\begin{array}{c}\text { Units of } \\
\text { measurement }\end{array}$ \\
\hline Average annual number of employees, in total & pers \\
\hline Number of personnel at the beginning of year & pers \\
\hline Hired & pers \\
\hline Fired, including & pers \\
\hline On one's own volition & pers \\
\hline For any breaches & pers \\
\hline Number of personnel at the end of year & pers \\
\hline Average headcount of personnel & pers \\
\hline Turnover coefficient for the employees hiring & \\
\hline Turnover coefficient for the employees quitting & \\
\hline Turnover rate of personnel & \\
\hline Stability factor of personnel & \\
\hline Labour efficiency per one employee & RUB, \\
\hline Positions quantity & in thousands \\
\hline Departments quantity & pcs \\
\hline Average monthly salary of an employee & RUB, \\
\hline
\end{tabular}




\begin{tabular}{|c|c|}
\hline & in thousands \\
\hline Wage and salaries fund & mln. RUB \\
\hline Wage and salaries fund towards total revenue & $\%$ \\
\hline Net income per one employee & $\begin{array}{c}\text { RUB, } \\
\text { in thousands }\end{array}$ \\
\hline Initial capital, in total & mln. RUB \\
\hline including: equity & mln. RUB \\
\hline debt & mln. RUB \\
\hline Cost price of all types of products & mln. RUB \\
\hline Revenues from sales of all types of products & mln. RUB \\
\hline Profit on sales of all types of products & mln. RUB \\
\hline Taxes, in total & mln. RUB \\
\hline including: VAT & mln. RUB \\
\hline Property tax & mln. RUB \\
\hline Profit tax & mln. RUB \\
\hline Advertising tax & mln. RUB \\
\hline Payment for loan, in total & mln. RUB \\
\hline including interest on a loan & mln. RUB \\
\hline Net income of a company, in total & mln. RUB \\
\hline including: net profit & mln. RUB \\
\hline amortization & mln. RUB \\
\hline Company development fund & mln. RUB \\
\hline including: on net profit & mln. RUB \\
\hline amortization & mln. RUB \\
\hline Operating cash reserve & mln. RUB \\
\hline Planned dividends & mln. RUB (\%) \\
\hline Project economic effect (NPV) & mln. RUB \\
\hline Internal rate of return (IRR) & $\%$ \\
\hline Modified internal rate of return (MIRR) & $\%$ \\
\hline Average annual production capacity & $\begin{array}{l}\text { RUB, in } \\
\text { thousands }\end{array}$ \\
\hline Scope of production & $\begin{array}{l}\text { RUB, in } \\
\text { thousands }\end{array}$ \\
\hline Commercial products & mln. RUB \\
\hline Average annual number of PPP & pers \\
\hline Total cost of products & mln. RUB \\
\hline Average annual cost of fixed capital stock (OPF) & mln. RUB \\
\hline \multicolumn{2}{|l|}{ Derived indices } \\
\hline Costs for a unit of commercial products & RUB \\
\hline Commercial products per 1 employee & $\begin{array}{l}\text { RUB, in } \\
\text { thousands }\end{array}$ \\
\hline Yield on capital investments & RUB \\
\hline Profit & mln. RUB \\
\hline Economic efficiency & $\%$ \\
\hline
\end{tabular}

Modern approaches for the development of key indices of virtual divisions performance, such as Balanced Scorecard (BSC) require that the divisions indices comply with their performance conditions.

First of all, such indices shall comply with the company strategy. To achieve this point, at first stage the Chief shall set the strategic purposes through the strategic key indices that will be planned, monitored and controlled by the Chief. BSC method means 15-20 strategic purposes, which shall be set relating to all the company operation aspects.

Balanced Scorecard (SSP, BSC) is the method of the personnel sequential familiarization with the development strategy, company purposes and control of their 
achievement using the key performance indices (KPI). Four groups of the strategic purposes are provided as standard: financial, client, process, and the fourth group is the purposes relating to personnel and other resources, including the information system, material, financial and administrative resources [10].

Similar to strategic purposes and key indices, the company divisions shall have four groups of indices: financial, client, process and resource [13].

The most relevant cost items, on which the division may have an impact, serve as the financial indices of any division.

It is also necessary to develop the client indices for each company division, measuring the satisfaction of external and internal consumers, quality of work results performed by division, their timeliness and compliance with the different requirements specified [14].

Process indices of the company division measure the processes and functions performed by division. In particular, time period for their execution, productive capacity, quality of execution, and compliance of execution procedures with the requirements specified.

The last group of resource indices describes the division personnel competency, its satisfaction, productive capacity [15]. This group also includes the indices, which describe the information resource - the level of division automatization, etc.

\section{Discussion}

Based on the materials presented in this work, we are talking about a new level of development of the system of "man-machines", where it becomes possible to migrate physical functions in virtual Wednesday. First of all, the above listed indices of the project division work efficiency mean the measurability of result, it means that it may be measured in numbers or in money costs. The peculiarity of virtual organization work is that a part of cooperation between the employees/partners is strictly subjective, it often reposes on trust. The high-priority task when choosing the virtual form of organization is solving of initial matters relating to the working hours distribution, method of payment for labour, personnel hiring and management, commitment to the company ideology. Performance indices of virtual divisions will create the aggregate picture of Project Company's work in the construction.

\section{Conclusion}

In spite of the existing development in the field of computer-aided design, using a virtual forms of work not so widespread because of the difficulty of constructing a model of work and lack of a clear algorithm staff interactions. You may be prompted to design process decomposition into constituent elements and to increase the level of each virtualization, as well as other workflows. Synthesis of real Russian and foreign experience to establish a fully virtual enterprise gives the background to the fact that when you find the necessary mechanisms work, this model will be developed and construction.

\section{References}

1. S.N. Bolshakov, S.A. Sinenko, A.Y. Slavina, Industrial and civil construction 8, 87-91 (2016)

2. A.V. Kataev, Polytechnic University Publ., 120 (2009)

3. M. Warner, M. Vytzel, New forms of doing business in the XXI century (Moscow, 2005) 
4. A.Y. Slavina, Virtual and augmented reality-2016, 308-314 (2016)

5. A.V. Kataev, Materials of XLVII scientific and technical Conference 1(24), 182-185 (2002)

6. S.N. Bolshakov, Vestnik MGSU 13, 287-294 (2013)

7. E.N. Tkatcheva, Functional contents and principles of management, 25 (2006)

8. V.A. Serdyuk, Management in Russia and abroad 2, 25-37 (2012)

9. V. Meitus, Control theory and practice issues 1, 91-95 (2004)

10. E.B. Kolesnikova, T.K. Kuz'mina, S.A. Synenko, Construction, 51 (2015)

11. W. Saabeel, Virtualness 4, 1 (2004)

12. http://www.kom-dir.ru/article/1457-pokazateli-effektivnosti-deyatelnosti

13. S.N. Bolshakov, A.A. Volkov, Vestnik MGSU 11, 218-225 (2013)

14. M. Kamennova, A. Gromov, Open systems, 4 (2000)

15. S. Kovalev, V. Kovalev, Practice for organization design (BITEK, Moscow, 2014) 